\title{
Long-term follow-up of localized, primary gastric diffuse large B-cell lymphoma treated with rituximab and CHOP
}

\author{
YUJIN KOBAYASHI $^{1}$, YOSHIHIRO HATTA ${ }^{1}$, ATSUKO HOJO $^{1}$, YOSHIMASA KURA ${ }^{3}$, YOSHIHITO UCHINO ${ }^{1}$, \\ HIROMICHI TAKAHASHI ${ }^{1}$, SATOMI KISO ${ }^{1}$, YUKIO HIRABAYASHI ${ }^{1}$, MAI YAGI ${ }^{1}$, HITOMI KODAIRA ${ }^{1}$, \\ DAISUKE KURITA $^{1}$, TOSHITAKE TANAKA ${ }^{1}$, KATSUHIRO MIURA ${ }^{1}$, NORIYOSHI IRIYAMA ${ }^{1}$, \\ SUMIKO KOBAYASHI $^{1}$, UMIHIKO SAWADA ${ }^{3}$, MASAHIKO SUGITANI ${ }^{2}$ and JIN TAKEUCHI $^{1}$ \\ Departments of ${ }^{1}$ Hematology and Rheumatology, and ${ }^{2}$ Pathology, Nihon University School of Medicine, \\ 30-1 Oyaguchi-Kamicho, Itabashi-ku, Tokyo $173-8610 ;^{3}$ Department of Hematology and Oncology, \\ Kasukabe Municipal Hospital, 7-2-1 Chuo Kasukabe, Saitama 344-8588, Japan
}

Received September 16, 2011; Accepted November 10, 2011

DOI: 10.3892/etm.2011.387

\begin{abstract}
The addition of rituximab to cyclophosphamide, doxorubicin, vincristine and prednisone [CHOP (i.e., R-CHOP)] is considered to be the standard regimen for treating localized, primary gastric diffuse large B-cell lymphoma (PG-DLBCL). However, few studies have reported the long-term efficacy of R-CHOP therapy in the management of localized PG-DLBCL. In the present study, we performed a retrospective analysis of 11 patients with localized PG-DLBCL, who were treated with R-CHOP at Nihon University Itabashi Hospital and Kasukabe Municipal Hospital (Japan) from 2001 to 2008. Limited stage cancer was defined as stage I/II according to the Lugano staging system for gastrointestinal (GI) lymphomas. The relative dose intensity (RDI) of CHOP therapy was calculated for each patient. The median age of the patients was 68 years (range, 48-82). Gastralgia and anemia were common symptoms at initial presentation. All patients except 1 received 6 cycles of R-CHOP treatment without consolidative radiation therapy or prior surgery. RDI was maintained at over $80 \%$ in 9 out of 11 patients. All patients achieved complete remission and the estimated overall survival with a median follow-up of 54 months (range, 39-103) was $100 \%$, without relapse or significant GI adverse effects, such as perforation or bleeding during R-CHOP treatment. No long-term adverse effects of rituximab were recorded during the observation period. Helicobacter pylori infection was diagnosed in $72.7 \%$ ( 8 cases) of the patients, but was eradicated in a limited number of patients. Our data suggest
\end{abstract}

Correspondence to: Dr Yujin Kobayashi, Department of Hematology and Rheumatology, Nihon University School of Medicine, 30-1 Oyaguchi-Kamicho, Itabashi-ku, Tokyo 173-8610, Japan E-mail: eumagene@gmail.com

Key words: primary gastric diffuse large B-cell lymphoma, relative dose intensity, Helicobacter pylori, R-CHOP the feasibility and effectiveness of the addition of rituximab to conventional CHOP therapy in the management of localized PG-DLBCL.

\section{Introduction}

Primary non-Hodgkin's lymphoma of the gastrointestinal (GI) tract represents 3-4\% of all malignancies arising in the digestive tract. The most commonly involved site is the stomach $(60 \%$ of cases) (1). Primary gastric diffuse large B-cell lymphoma (PG-DLBCL) has been treated with various modalities, including surgery, chemotherapy and radiotherapy alone or in combination with other methods. Chemotherapy using cyclophosphamide, doxorubicin, vincristine and prednisone (CHOP) or CHOP-like regimens is considered to be the treatment of choice, due to its preferable outcomes (2-5). On the contrary, surgery, which until a few decades ago was deemed an essential first-line therapeutic intervention, is now relegated to patients with massive bleeding or perforation at presentation. Several studies have demonstrated that the extent of surgery has no impact on the outcome of GI lymphoma (6); it is now believed that non-surgical treatments achieve equal or better results than gastrectomy (7).

Rituximab, an anti-CD20 monoclonal antibody, has emerged as an effective therapy for numerous CD20-positive hematological malignancies (8). Highly promising results have been obtained in combination with chemotherapy, and the results of a randomized study comparing rituximab in addition to $\mathrm{CHOP}$ (R-CHOP) with CHOP alone in nodal DLBCL patients have shown superior response and survival rates for the R-CHOP regimen (9). Although the impact of the addition of rituximab to chemotherapy regimens has not been tested by conducting large clinical trials in patients with PG-DLBCL (10), its addition is considered preferable owing to proven therapeutic benefits in nodal DLBCL patients (11-12).

Taking these data into account, R-CHOP has been used increasingly as the primary treatment for patients with localized PG-DLBCL. To the best of our knowledge, only few studies reporting the long-term efficacy of the $\mathrm{R}-\mathrm{CHOP}$ regimen in 
this cohort have been published, with a median follow-up of 15 months (range, 4-42) (10). We performed a retrospective analysis of patients diagnosed with localized PG-DLBCL and treated with the R-CHOP regimen in the Nihon University Itabashi Hospital and Kasukabe Municipal Hospital (Japan), with a longer median follow-up of 54 months (range, 39-103). This study investigated the feasibility and effectiveness of the addition of rituximab to conventional CHOP therapy in the management of localized PG-DLBCL.

\section{Patients and methods}

Patients with localized PG-DLBCL undergoing treatment with R-CHOP, from January 2001 to December 2008, at the Nihon University Itabashi Hospital and Kasukabe Municipal Hospital were analyzed. All patients diagnosed with PG-DLBCL underwent esophagogastroduodenoscopy, and biopsy samples were obtained. Whole-body computed tomography (CT) scanning and bone marrow aspiration were included as lymphoma staging procedures. Positron emission tomography or gallium scanning were also used for staging. Colonoscopy was not routinely performed. The stage at presentation was assessed according to the Lugano staging system, and the localized stage was defined as stage I/II (13). Histologically, DLBCL was defined according to the criteria outlined in the WHO classification (14). A proton pump inhibitor (PPI) or histamine $\mathrm{H} 2$ receptor antagonist was used for treatment. The urea breath test (15), enzyme-linked immunosorbent assay (serological test to detect IgG antibodies) (16-17), biopsy urease test (18) or histological examinations were used to investigate the presence of Helicobacter pylori (H. pylori) infection.

The standard R-CHOP regimen (day 1: rituximab $375 \mathrm{mg} / \mathrm{m}^{2}$, cyclosphosphamide $750 \mathrm{mg} / \mathrm{m}^{2}$, doxorubicin $50 \mathrm{mg} / \mathrm{m}^{2}$, vincristine $1.4 \mathrm{mg} / \mathrm{m}^{2}$ and days 1-5: prednisone $40 \mathrm{mg} / \mathrm{m}^{2}$ ) was aimed to be administered at 21-day intervals. All patients were subjected to 6 curative cycles, and each cycle was repeated every 3 weeks. Following completion of treatment, re-evaluation of the treatment response by gastroscopy with biopsy and CT of the thorax and abdomen was performed. Response criteria were adapted from the international consensus reported by Cheson et al (19). Toxicities during treatment were evaluated according to the National Cancer Institute common toxicity criteria scale (version 3.0).

Relative dose intensity (RDI). In order to estimate the dose of antitumor agents, the RDI of CHOP was calculated as previously described by Epelbaum et al (20). Firstly, the planned full dose of the drug per cycle $\left(\mathrm{mg} / \mathrm{m}^{2}\right)$ was divided by the scheduled number of weeks in the cycle (week). Secondly, in order to determine the actual DI for each drug, the total dose of drug actually received by the patient $\left(\mathrm{mg} / \mathrm{m}^{2}\right)$ was divided by the total number of weeks actually required to receive the total dose (week). Thirdly, the actual DI of each drug was divided by the standard DI of the same drug. Fourthly, the average RDI of CHOP was calculated as the sum of RDI of cyclophosphamide, doxorubicin, vincristine and prednisone and divided by 4 . In total, in the present study, 6 cycles of standard CHOP regimen administered on 21-day intervals was regarded as full RDI (100\%). Rituximab was not included in the calculation.

\section{Results}

Our study identified 11 patients ( 7 females and 4 males) aged 48-82 years (median 68), who were administered R-CHOP for the treatment of localized PG-DLBCL (Table I). No patients were HIV-positive. All patients were chemosensitive and none had undergone prior surgery. All patients, except patient number 6 , were subjected to 6 cycles of R-CHOP therapy. A total of 8 patients displayed evidence of $H$. pylori infection at diagnosis.

At initial presentation, $7 / 11(63.6 \%)$ patients had gastralgia (abdominal pain) and 5/11 (45.4\%) had anemia (defined as hemoglobin levels below $14 \mathrm{~g} / \mathrm{dl}$ in males and $12 \mathrm{~g} / \mathrm{dl}$ in females), but no patients had hematemesis or melena. Weight loss, defined as the B-symptom, was found in 4/11 (36.4\%) patients (21). All 11 patients $(100 \%)$ achieved a complete response (CR). During the observation period with a median follow-up of 54 months (range, 39-103) following treatment, no patients succumbed to the disease or experienced relapse. Patient number 1 experienced gastric adenocarcinoma while in continuous CR 8 months following chemotherapy and was subsequently treated with a successful endoscopic mucosal resection. Patient number 3 experienced a cerebral infarction unrelated to lymphoma while in continuous CR, 51 months following the start of chemotherapy. No patients received additional radiation therapy. Patient number 2 received a reduced dose of CHOP therapy due to old age, organ dysfunction and poor performance status during initial treatment.

Acute toxicity associated with R-CHOP therapy, which was mainly hematological in nature, was mostly tolerated by patients. A total of 9/11 (81.8\%) patients developed granulocytopenia of grade 3-4 during treatment and 4/11 (36.4\%) patients developed febrile neutropenia or infection with grade 3-4 neutropenia. Patient number 6 developed recurrent septicemia (Escherichia coli or candidemia) during the first and second cycle of CHOP treatment, respectively, necessitating the cancellation of subsequent CHOP therapy. RDI was maintained at over $80 \%$ in the majority of patients, except patients number 2 and 6 due to comorbidities and infection. No GI bleeding or gastric perforations were noted. Reactions to rituximab were only mild with standard premedication. No signs of late rituximab toxicity such as viral infections or late-onset neutropenia were observed.

\section{Discussion}

Treatment for PG-DLBCL has shifted from surgery to gastric preservation methods, including chemotherapy and/or radiotherapy, in order to aid organ conservation. Certain retrospective and prospective studies have suggested that gastrectomy is unnecessary $(4,22-24)$ except during serious complications such as perforation, obstruction and hemorrhaging during non-surgical treatments. However, these analyses were performed prior to the introduction of rituximab. All patients treated with R-CHOP at our institution responded to treatment, and had continuous CR, which suggests that PG-DLBCL, similar to nodal DLBCL, is a highly chemosensitive and potentially curable disease. No adverse effects such as bleeding or perforation were observed in the patients included in this study, who were all administered concomitant therapy with oral PPIs or histamine $\mathrm{H} 2$ receptor antagonist on a routine basis. 


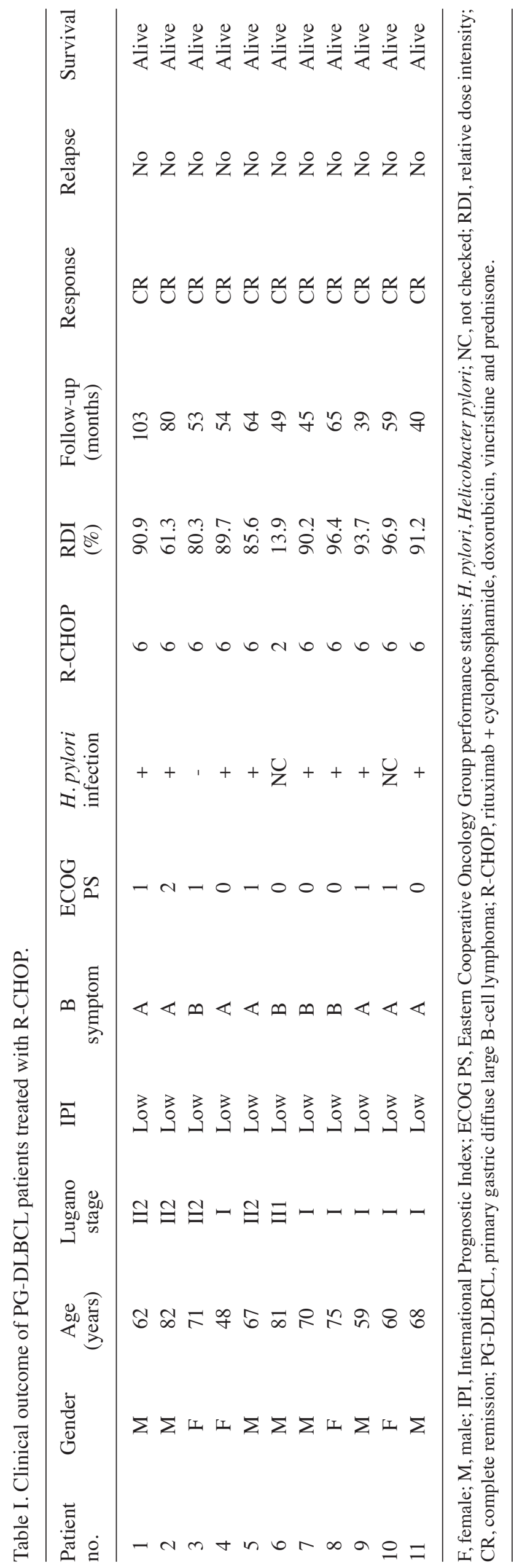

It is believed that the initial treatment of DLBCL should be maintained to the same dosage schedule for older individuals as for younger adults (25). We previously reported that older patients with DLBCL may be treated with standard R-CHOP, the same as younger patients if their comorbid condition is tolerable (26). Recently, the entity of the RDI was proposed as an index of the intensity of chemotherapy. Hirakawa et al previously reported that RDI maintenance in the chemotherapy of DLBCL improved the treatment results even in the rituximab era (27). They showed that an actual RDI of less than 70\% was an independent prognostic factor for a low overall and progression-free survival. A high RDI maintained among the majority of patients in this study was considered to be one of the possible causes of favorable long-term otucome.

A prospective, randomized study carried out by Bonnet et al, which compared CHOP alone with CHOP plus radiotherapy, involved field radiation in almost 600 patients older than 60 years of age, with aggressive lymphoma of stages I and II (28). However, only a small number of gastric lymphomas were examined in this study. There was no advantage of combined treatment over chemotherapy alone regarding 5 -year event-free and overall survival. As in other types of DLBCL, the standard regimen of primary gastric DLBCL in its early stages is currently rituximab in combination with CHOP (9). Patients with more limited gastric lesions (diameter of less than $5 \mathrm{~cm}$ ) have previously been treated with radiotherapy alone (29); however, at present these patients are also treated with combined modality treatment (i.e. chemotherapy and radiotherapy) (30). The precise role of radiotherapy in gastric DLBCL is still an issue of debate as most data in the literature come from retrospective studies. It is possible that additional radiation may be restricted to patients with low grade mucosa associated lymphoid tissue (MALT) components not responding to $H$. pylori eradication therapy, as well as patients with DLBCL and a bulky tumor (31).

Among the 11 patients, 8 (72.7\%) were positive for $H$.pylori infection (1 negative and 2 not checked). In Japan, more than $70-80 \%$ of adults born before 1950 , and $45 \%$ of those born after 1950 are infected with $H$. pylori (32). Moreover, the number of siblings is also linked to a higher acquisition of H. pylori infection $(33,34)$. In the present study, 10 out of the 11 patients were born prior to 1950 , and the average number of siblings of all patients was 3.7 (data not shown). H. pylori eradication was not routinely performed at our institution due to histological evidence of DLBCL and the priority that R-CHOP therapy be initiated immediately upon diagnosis. In contrast to gastric MALT lymphoma, the role of H.pylori infection in PG-DLBCL is controversial. As reported previously, H. pylori eradication resulted in durable histologically confirmed CR in 50-63\% of patients with gastric DLBCL and concomitant MALT (35). The eradication of $H$. pylori may be necessary in PG-DLBCL, particularly in cases of concomitant MALT lymphoma (36).

The most common documented adverse event associated with rituximab is an acute infusion reaction (37). However, with the increase in the number of patients treated with rituximab, long-term hematological or infectious adverse events occurring following the administration of rituximab have been reported more frequently (8). A recently published systematic review evaluating infectious complications of monoclonal 
antibodies administered in cancer patients failed to demonstrate a significant increase in the incidence of infections with the addition of rituximab to chemotherapy (38). Despite some controversies, we believe that close monitoring of patients receiving rituximab enables us to use rituximab safely.

Avilés et al recently reported the results of a phase II clinical trial to assess the efficacy and toxicity of the addition of rituximab to chemotherapy in cases of primary gastric lymphoma (PGL). They concluded that the addition of rituximab to CHOP chemotherapy did not improve the outcome in cases of low clinical risk, early-stage PGL with a favorable outcome of 5-year overall survival of $95 \%$, compared with historical controls treated with CHOP monotherapy (39). Some limitations of this study included the small number of patients participating in the study and that conclusions were based upon the comparison with historical controls (4). A recent report by Leopardo et al detailed a retrospective study of stage I-IV gastric DLBCL patients treated with rituximab plus chemotherapy versus chemotherapy alone (40). They concluded that rituximab plus chemotherapy yielded a statistically significant advantage in terms of continuous CR (100 vs. $76.6 \%, \mathrm{P}=0.004)$ at 5 years. A poor outcome with chemotherapy alone may have resulted from the fact that advanced diseases, which were graded stage III-IV in the Lugano staging system, were included in this study.

Two innovative methods to observe the entire small intestine were recently introduced: wireless capsule endoscopy (WCE) and double-balloon enteroscopy (DBE) (41). The two modalities enable high-resolution visualization of the entire small intestine in order to detect lymphoma. Since WCE or DBE were not routinely available during the present study, the exact frequency of lymphoma involvement in the small intestine is unknown. In contrast to follicular lymphoma in the GI tract, the frequency of small intestine involvement in gastric DLBCL is not precisely known. Further investigation with WCE or DBE will be useful for accurately evaluating disease distribution in the case of GI-tract lymphoma.

Although the outcome of adding rituximab to $\mathrm{CHOP}$ therapy should be evaluated by a large-scale randomized trial, difficulties collecting prospective data associated with this rare malignancy may prevent such an undertaking. In clinical practice, rituximab is usually combined with CHOP-like regimens as in the case of nodal DLBCL therapy (42). Our results demonstrate the feasibility and effectiveness of the addition of rituximab to conventional $\mathrm{CHOP}$ therapy in the management of localized PG-DLBCL, and suggest that R-CHOP be considered as a standard clinical treatment in patients with localized PG-DLBCL.

\section{Acknowledgements}

We would like to thank to Ms. Mako Sonobe and Shiori Hirasawa for administrative support.

\section{References}

1. Tondini C, Giardini R, Bozzetti F, Valagussa P, Santoro A Bertulli R, Balzarotti M, Rocca A, Lombardi F, Ferreri AJ and Bonadonna G: Combined modality treatment for primary gastrointestinal non-Hodgkin's lymphoma: the Milan Cancer Institute experience. Ann Oncol 4: 831-837, 1993.
2. Binn M, Ruskoné-Fourmestraux A, Lepage E, Haioun C, Delmer A, Aegerter P, Lavergne A, Guettier C and Delchier JC: Surgical resection plus chemotherapy versus chemotherapy alone: comparison of two strategies to treat diffuse large B-cell gastric lymphoma. Ann Oncol 14: 1751-1757, 2003.

3. Yoon SS, Coit DG, Portlock CS and Karpeh MS: The diminishing role of surgery in the treatment of gastric lymphoma. Ann Surg 240: 28-37, 2004.

4. Avilés A, Nambo MJ, Neri N, Huerta-Guzmán J, Cuadra I, Alvarado I, Castañeda C, Fernández R and González M: The role of surgery in primary gastric lymphoma: results of a controlled clinical trial. Ann Surg 240: 44-50, 2004.

5. Koch P, Probst A, Berdel WE, Willich NA, Reinartz G, Brockmann J, Liersch R, del Valle F, Clasen H, Hirt C, et al: Treatment results in localized primary gastric lymphoma: data of patients registered within the German multicenter study (GIT NHL 02/96). J Clin Oncol 23: 7050-7059, 2005.

6. Psyrri A, Papageorgiou S and Economopoulos T: Primary extranodal lymphomas of stomach: clinical presentation, diagnostic pitfalls and management. Ann Oncol 19: 1992-1999, 2008

7. Ferreri AJ and Montalbán C: Primary diffuse large B-cell lymphoma of the stomach. Crit Rev Oncol Hematol 63: 65-71, 2007.

8. Ram R, Ben-Bassat I, Shpilberg O, Polliack A and Raanani P: The late adverse events of rituximab therapy - rare but there! Leuk Lymphoma 50: 1083-1095, 2009.

9. Coiffier B, Lepage E, Briere J,Herbrecht R, Tilly H, Bouabdallah R, Morel P, van den Neste E, Salles G, Gaulard P, Reyes F, Lederlin P and Gisselbrecht C: CHOP chemotherapy plus rituximab compared with CHOP alone in elderly patients with diffuse large-B-cell lymphoma. N Engl J Med 346: 235-242, 2002.

10. Wöhrer S, Püspök A, Drach J, Hejna M, Chott A and Raderer M: Rituximab, cyclophosphamide, doxorubicin, vincristine and prednisone (R-CHOP) for treatment of early-stage gastric diffuse large B-cell lymphoma. Ann Oncol 15: 1086-1090, 2004.

11. Habermann TM, Weller EA, Morrison VA, Gascoyne RD, Cassileth PA, Cohn JB, Dakhil SR, Woda B, Fisher RI, Peterson BA and Horning SJ: Rituximab-CHOP versus CHOP alone or with maintenance rituximab in older patients with diffuse large B-cell lymphoma. J Clin Oncol 24: 3121-3127, 2006.

12. Feugier P, van Hoof A, Sebban C, Solal-Celigny P, Bouabdallah R, Fermé C, Christian B, Lepage E, Tilly H, Morschhauser F, et al: Long-term results of the R-CHOP study in the treatment of elderly patients with diffuse large B-cell lymphoma: a study by the Groupe d'Etude des Lymphomes de l'Adulte. J Clin Oncol 23: 4117-4126, 2005.

13. Rohatiner A, d'Amore F, Coiffier B, Crowther D, Gospodarowicz M, Isaacson P, Lister TA, Norton A, Salem P, Shipp M and Somers R: Report on a workshop convened to discuss the pathological and staging classifications of gastrointestinal tract lymphoma. Ann Oncol 5: 397-400, 1994.

14. Gatter KCWR: Diffuse large cell lymphoma. In: World Health Organization Classification of Tumours: Tumours of Haematopoietic and Lymphoid Tissues. Jaffe ES, Harris NL, Sha VJ (eds). IARC Press, Lyon, pp171-176, 2001.

15. Leide-Svegborn S, Stenström K, Olofsson M, Mattsson S, Nilsson LE, Nosslin B, Pau K, Johansson L, Erlandsson B, Hellborg R and Skog G: Biokinetics and radiation doses for carbon-14 urea in adults and children undergoing the Helicobacter pylori breath test. Eur J Nucl Med 26: 573-580, 1999.

16. Chey WD and Wong BC; Practice Parameters Committee of the American College of Gastroenterology: American College of Gastroenterology guideline on the management of Helicobacter pylori infection. Am J Gastroenterol 102: 1808-1825, 2007.

17. Malfertheiner P, Megraud F, O'Morain C, Bazzoli F, El-Omar E, Graham D, Hunt R, Rokkas T, Vakil N and Kuipers EJ: Current concepts in the management of Helicobacter pylori infection: the Maastricht III Consensus Report. Gut 56: 772-781, 2007.

18. Laine L, Lewin D, Naritoku W, Estrada R and Cohen H: Prospective comparison of commercially available rapid urease tests for the diagnosis of Helicobacter pylori. Gastrointest Endosc 44: 523-526, 1996.

19. Cheson BD, Pfistner B, Juweid ME, Gascoyne RD, Specht L, Horning SJ, Coiffier B, Fisher RI, Hagenbeek A, Zucca E, et al; International Harmonization Project on Lymphoma: Revised response criteria for malignant lymphoma. J Clin Oncol 25: 579-586, 2007.

20. Epelbaum R, Haim N, Ben-Shahar M, Ron Y and Cohen Y: Dose-intensity analysis for CHOP chemotherapy in diffuse aggressive large cell lymphoma. Isr J Med Sci 24: 533-538, 1998. 
21. Anderson T, Chabner BA, Young RC, Berard CW, Garvin AJ, Simon RM and DeVita VT Jr: Malignant lymphoma. 1. The histology and staging of 473 patients at the National Cancer Institute. Cancer 50: 2699-2707, 1982.

22. Papaxoinis G, Papageorgiou S, Rontogianni D, Kaloutsi V, Fountzilas G, Pavlidis N, Dimopoulos M, Tsatalas C, Xiros N and Economopoulos T: Primary gastrointestinal non-Hodgkin's lymphoma: a clinicopathologic study of 128 cases in Greece. A Hellenic Cooperative Oncology Group study (HeCOG). Leuk Lymphoma 47: 2140-2146, 2006.

23. Willich NA, Reinartz G, Horst EJ, Delker G, Reers B, Hiddemann W, Tiemann M, Parwaresch R, Grothaus-Pinke B, Kocik J and Koch P: Operative and conservative management of primary gastric lymphoma: interim results of a German multicenter study. Int J Radiat Oncol Biol Phys 46: 895-901, 2000

24. Coiffier B and Salles G: Does surgery belong to medical history for gastric lymphomas? Ann Oncol 8: 419-421, 1997.

25. Thieblemont $\mathrm{C}$ and Coiffier B: Lymphoma in older patients. J Clin Oncol 25: 1916-1923, 2007

26. Kobayashi Y, Miura K, Hojo A, Hatta Y, Tanaka T, Kurita D, Iriyama N, Kobayashi S and Takeuchi J: Charlson Comorbidity Index is an independent prognostic factor among elderly patients with diffuse large B-cell lymphoma. J Cancer Res Clin Oncol 137: 1079-1084, 2011.

27. Hirakawa T, Yamaguchi H, Yokose N, Gomi S, Inokuchi K and Dan K: Importance of maintaining the relative dose intensity of CHOP-like regimens combined with rituximab in patients with diffuse large B-cell lymphoma. Ann Hematol 89: 897-904, 2010.

28. Bonnet C, Fillet G, Mounier N, Ganem G, Molina TJ Thiéblemont C, Fermé C, Quesnel B, Martin C, Gisselbrecht C, Tilly $\mathrm{H}$ and Reyes F; Groupe d'Etude des Lymphomes de l'Adulte: CHOP alone compared with CHOP plus radiotherapy for localized aggressive lymphoma in elderly patients: a study by the Groupe d'Etude des Lymphomes de l'Adulte. J Clin Oncol 25: 787-792, 2007.

29. Taal BG, Burgers JM, van Heerde P, Hart AA and Somers R: The clinical spectrum and treatment of primary non-Hodgkin's lymphoma of the stomach. Ann Oncol 4: 839-846, 1993.

30. Aleman BM, Haas RL and van der Maazen RW: Role of radiotherapy in the treatment of lymphomas of the gastrointestinal tract. Best Pract Res Clin Gastroenterol 24: 27-34, 2010.

31. Fischbach W: Long-term follow-up of gastric lymphoma after stomach conserving treatment. Best Pract Res Clin Gastroenterol 24: 71-77, 2010.
32. Asaka M, Kimura T, Kudo M, Takeda H, Mitani S, Miyazaki T, Miki K and Graham DY: Relationship of Helicobacter pylori to serum pepsinogens in an asymptomatic Japanese population. Gastroenterology 102: 760-766, 1992.

33. Webb PM, Knight T, Greaves S, Wilson A, Newell DG, Elder J and Forman D: Relation between infection with Helicobacter pylori and living conditions in childhood: evidence for person to person transmission in early life. BMJ 308: 750-753, 1994.

34. Kivi M, Johansson AL, Reilly M and Tindberg Y: Helicobacter pylori status in family members as risk factors for infection in children. Epidemiol Infect 133: 645-652, 2005.

35. Chen LT, Lin JT, Tai JJ, Chen GH, Yeh HZ, Yang SS, Wang HP, Kuo SH, Sheu BS, Jan CM, et al: Long-term results of anti-Helicobacter pylori therapy in early-stage gastric high-grade transformed MALT lymphoma. J Natl Cancer Inst 97: 1345-1353, 2005.

36. Raderer M, Chott A, Drach J, Montalban C, Dragosics B, Jäger U, Püspök A, Osterreicher C and Zielinski CC: Chemotherapy for management of localised high-grade gastric B-cell lymphoma: how much is necessary? Ann Oncol 13: 1094-1098, 2002.

37. Winkler U, Jensen M, Manzke O, Schulz H, Diehl V and Engert A: Cytokine-release syndrome in patients with B-cell chronic lymphocytic leukemia and high lymphocyte counts after treatment with an anti-CD20 monoclonal antibody (rituximab, IDEC-C2B8). Blood 94: 2217-2224, 1999.

38. Rafailidis PI, Kakisi OK, Vardakas K and Falagas ME: Infectious complications of monoclonal antibodies used in cancer therapy: a systematic review of the evidence from randomized controlled trials. Cancer 109: 2182-2189, 2007.

39. Avilés A, Castañeda C, Cleto S, Neri N, Huerta-Guzmán J and Gonzalez M: Rituximab and chemotherapy in primary gastric lymphoma. Cancer Biother Radiopharm 24: 25-28, 2009.

40. Leopardo D, Di Lorenzo G, De Renzo A, Federico P, Luponio S, Buonerba C, Matano E, Merola G, Imbimbo M, Montesarchio E, et al: Efficacy of rituximab in gastric diffuse large B cell lymphoma patients. World J Gastroenterol 16: 2526-2530, 2010.

41. Yamamoto S, Nakase H, Yamashita K, Matsuura M, Takada M, Kawanami C and Chiba T: Gastrointestinal follicular lymphoma: review of the literature. J Gastroenterol 45: 370-388, 2010

42. Raderer M and Paul de Boer J: Role of chemotherapy in gastric MALT lymphoma, diffuse large B-cell lymphoma and other lymphomas. Best Pract Res Clin Gastroenterol 24: 19-26, 2010. 